\title{
ESTILOS COS
}

DOI: https://doi.org/10.11606/issn.1981-1624.v25i2 p193-209.

\section{Dossiê}

\section{Imaginários de mulheres que sofreram perda gestacional}

\author{
Carlos Del Negro Visintin; Gisele Meirelles Fonseca Inacarato; Tânia Maria José Aiello- \\ Vaisberg
}

Resumo. Inserido num conjunto maior de pesquisas sobre sofrimentos maternos, entendidos como socialmente determinados, este estudo objetiva investigar o imaginário coletivo de mulheres que sofreram perda gestacional, sobre esta ocorrência, na perspectiva da psicologia psicanalítica concreta. Justifica-se na medida em que pode lançar luz sobre uma situação relevante na clínica psicológica da maternidade, favorecendo a prática clínica em vertentes preventivas e interventivas. Organizada como pesquisa qualitativa com uso do método psicanalítico, esta investigação utilizou, como material, postagens em blogs brasileiros de 15 mulheres que relatam terem sofrido perda gestacional. A consideração psicanalítica dos escritos permitiu a produção interpretativa de dois campos de sentido afetivo-emocional: "É culpa da mãe" e "Vazio eterno". O quadro geral indica mulheres que sofrem perda gestacional tendem a habitar imaginários coletivos de acordo com os quais seriam as únicas responsáveis pelo ocorrido, o que provoca sentimentos de culpa e de vazio existencial.

Palavras chave: maternidade; método psicanalítico; imaginários coletivos.

\section{Imaginarios de mujeres que sufrieron pérdida de embarazo}

Resumen. Integrado a un conjunto más amplio de investigación sobre el sufrimiento materno, entendido como determinado socialmente, este estudio tiene como objetivo investigar el imaginario colectivo de las mujeres que han sufrido la pérdida del embarazo, desde la perspectiva de la psicología psicoanalítica concreta. Pretende arrojar luz sobre una situación relevante en la clínica psicológica de la maternidad, favoreciendo la práctica clínica en aspectos preventivos e intervencionistas. Organizada como una investigación cualitativa utilizando el método psicoanalítico, esta investigación utilizó, como material, publicaciones en blogs brasileños de mujeres que informan haber sufrido la pérdida del embarazo. La consideración psicoanalítica de los escritos permitió la producción interpretativa de dos campos de significado afectivo-emocional: "Es culpa de la madre" y "Vacío eterno". Se considera que estos campos ponen a la mujer en una situación imaginativa según la cual ella sería la única responsable de la pérdida del embarazo, lo que alentaría sentimientos de culpa y vacío.

Palabras-clave: maternidad; método psicoanalítico; imaginarios colectivos.

\footnotetext{
*Doutorando em psicologia (bolsista CNPq), Pontifícia Universidade Católica de Campinas, Campinas, SP, Brasil. Email: carlos.visintin@gmail.com

** Doutoranda em psicologia (bolsista CAPES), Pontifícia Universidade Católica de Campinas, Campinas, SP, Brasil. E-mail: giseleinacarato@gmail.com

*** Professora, Programa de Pós-Graduação em Psicologia, Pontifícia Universidade Católica de Campinas, Campinas, SP, Brasil. E-mail: aiello.vaisberg@gmail.com
} 


\title{
Imaginaries of women who experienced a pregnancy loss
}

\begin{abstract}
This study is part of a larger set of studies about maternal suffering, understood as socially determined. Its objective is to investigate the collective imaginary of women who experienced pregnancy loss, from the perspective of psychoanalytic concrete psychology. The importance of this study lies in its potential to shed light upon a situation that is relevant for psychological practice in the scope of motherhood, contributing to support preventive measures and interventions. This qualitative study adopted the psychoanalytical method to address Brazilian blogs authored by women reporting pregnancy loss. Two fields of affective-emotional meaning emerged from the psychoanalytical interpretation: "It's the mother's fault" and "Eternal void". Both fields convey the idea that women are the only ones accountable for gestational loss, leading to feelings of guilt and emptiness.
\end{abstract}

Keywords: motherhood; psychoanalytic method; collective imaginaries.

Inserido num conjunto de investigações sobre a maternidade, este trabalho objetiva investigar o imaginário coletivo de mulheres que sofreram perda gestacional, sobre esta ocorrência, na perspectiva da psicologia psicanalítica concreta, o que pode contribuir para a compreensão de sua experiência vivida. De acordo com a psicologia psicanalítica concreta, proposta por Bleger (1963/2007), todos os fenômenos humanos - inclusive a maternidade - e dificuldades relacionadas - devem ser entendidos como devidamente inseridos em contextos macrossociais, cujas dimensões históricas, sociais, geopolíticas, culturais e econômicas devem ser levadas em conta.

O fenômeno da maternidade conforma-se de modo complexo e multifacetado, tendo sido abordado a partir de diversas perspectivas. Tradicionalmente, o aspecto biológico é bastante valorizado, na pressuposição de que as mães biológicas estariam naturalmente preparadas para cuidarem dos filhos. Assim, a prática da maternidade é imaginada como fenômeno biológica e inatamente determinado, de modo que o conjunto de atividades que envolve, que são trabalho humano, no sentido preciso do termo, não é considerado como tal, não são devidamente consideradas (Bueskens,2018).

Para Hollway (2011), a configuração dos cuidados infantis, em nossa sociedade, expressa relações de gênero segundo um modelo no qual homens cuidam do sustento financeiro da família e as mulheres, da prole. Contudo, não podemos negar que o movimento feminista promoveu um questionamento sobre esta situação, permitindo reflexões sobre a desnaturalização da maternidade (Marchesi, 2018). Paralelamente, a entrada da mulher no mundo laboral é hoje uma realidade que atravessa classes sociais sem, entretanto, afetar o imaginário segundo o qual as crianças só teriam garantidas as melhores condições quando cuidadas diretamente pelas mães biológicas, que seguem, assim, carregando responsabilidade quase exclusiva pelos filhos (Scavone, 2004; Vásquez, 2014).

Do ponto de vista da psicologia psicanalítica concreta (Bleger, 1963/2007), compreendemos que as manifestações humanas ocorrem sempre em condições vinculares e sociais específicas. Entendendo a maternidade, por esta via, como produção social e cultural, estabelecemos diálogos com certos teóricos, como Badinter (1981, 2012) e Giddens (2013). Badinter (1981, 2012) apontou que, mesmo abolindo o conceito de instinto, a concepção inatista sobre a maternidade persiste sob a ideia do amor materno. A seu ver, a hipótese do amor inato deve ser recusada, pois medos e alegrias, relacionados à gestação, ao parto e aos cuidados infantis, são 
vividos em contexto históricos e culturais específicos, em meio aos quais sentidos são criados. Giddens (2013), por sua vez, debate que a equivalência entre ser mulher e ser mãe conformase como uma invenção social específica do mundo ocidental. Nessa perspectiva, consolidou-se a ideia, para usar termos do próprio autor, de que a mulher estaria naturalmente preparada para ser mãe. Em função dessa suposta capacidade, os cuidados com os filhos recairiam sobre as mulheres, cuja vida deveria restringir-se à maternidade. A nosso ver, tal prática tanto responsabiliza a mãe praticamente por todos os infortúnios, que possam afligir as novas gerações, quanto obtura o estabelecimento de relacionamentos mais estreitos e próximos de outras pessoas com a genetriz e suas crianças.

Entendemos, com o auxílio da literatura, que mães poderiam vir a se sentir culpadas e angustiadas em razão das pesadas exigências sociais deste modelo de cuidados de crianças, que as deixou em situação de dependência financeira e sob o poder dos cônjuges (Federici, 2019). A modificação ocorrida, a partir da entrada na vida profissional, não diminuiu as demandas, mas dobrou-as, configurando a chamada dupla jornada (Bueskens,2018). Estudando psicanaliticamente mommy blogs, Visintin e Aiello-Vaisberg (2017), constataram que perpassava, pelo material estudado, a fantasia de que a realização pessoal da mulher deveria atrelar-se obrigatoriamente à dedicação exclusiva aos filhos. Em pesquisa que adotou delineamento semelhantes, Schulte, Gallo-Belluzo e Aiello-Vaisberg (2019) desvelam uma situação na qual a mãe deveria tanto se dedicar aos filhos, quanto conciliar diversas outras atividades, entre as quais as de caráter profissional. Destarte, trabalhamos, neste estudo, com a noção de que sofrimentos maternos seriam socialmente determinados (Aiello-Vaisberg, 2017), compreensão que parece empiricamente correta, uma vez que várias pesquisas apontam o peso dos determinantes sociais nos sofrimentos de mães (Barr-Walker, Jayaweera, Ramirez, \& Gerdts, 2019; Collardeau et al. 2019; Hamad, Modrek \& White, 2019; Komtenza et al., 2019).

Estamos, portanto, diante de um contexto cultural que se coloca de modo ambíguo diante da questão do cuidado das crianças, na medida em que o concebe como derivado do instinto biológico, mas também como possibilidade da mulher de alcançar a valorização social possível para aquela que ocupa a posição inferior na hierarquia entre os gêneros. Compreende-se, então, que altas expectativas recaiam sobre a gestação. Ocorre, entretanto, que nem sempre a gravidez caminha bem, sendo que entre as várias intercorrências inserem-se as interrupções involuntárias, que provocam efeitos físicos e ressonâncias emocionais. O estudo de Mutiso, Murage e Mukaindo (2018) sugere que mães que sofreram perda gestacional estão mais propensas a desenvolverem sintomas depressivos e pensamentos de autolesão. Tavoli et al. (2018), por sua vez, afirmam que mulheres com histórico de perda gestacional sofrem maiores níveis de ansiedade e de depressão. Malgrado as limitações inerentes à abordagem positivista nas ciências humanas (Ambrosio,2013), consideramos que tais pesquisas indicam que a experiência de óbito fetal coloca a mulher numa circunstância que inspira cuidados clínicos em âmbitos médico e psicológico.

No que tange especificamente aos estudos psicológicos sobre perda fetal, podemos distinguir duas grandes tendências. Uma delas, composta por um número maior de produções, investiga a experiência vivida pela mulher, usando principalmente entrevistas psicológicas (Lemos \& Cunha, 2015; Camarneiro, Maciel \& Silveira, 2015), ou sua saúde mental, fazendo uso de testes e escalas (Cardoso-Escamilla, Zavala-Bonachea \& Alva-López, 2017). Uma segunda tendência 
investiga os profissionais da saúde que trabalham dando suporte as estas mulheres (Lemos \& Cunha, 2015; Tachibana, Ambrosio, Beaune \& Aiello-Vaisberg, 2014), também por meio de entrevistas psicológicas. O presente estudo se inclui na primeira tendência, optando, entretanto, por abordar a questão a partir do estudo de blogs, por meio dos quais pessoas, que eventualmente não buscaram ajuda psicológica, nem foram convidadas a participar de pesquisas, apresentam suas experiências voluntariamente, de forma pública e, portanto, acessível, ao pesquisador/psicanalista interessado em produzir conhecimento compreensivo sobre sentidos afetivo-emocionais do acontecer humano, em âmbitos individuais e coletivos (Schulte, Gallo-Belluzzo \& Aiello-Vaisberg, 2019).

A fim de propormos o presente trabalho, partimos da experiência vivida de mulheres que sofreram uma perda gestacional. Trata-se de uma situação cujo estudo podem lançar luz sobre a questão da maternidade, uma vez que a interrupção gestacional involuntária coloca a mulher diante da impossibilidade de ser mãe, ao menos daquele bebê. Quando a maternidade fica impedida, constela-se uma configuração que pode revelar-se, por ser o oposto daquilo que é buscado, como oportunidade de compreensão maior do que é culturalmente hegemônico. Assim, a perda gestacional pode contribuir para evidenciar o lugar que a maternidade ocupa no imaginário das pessoas e dos grupos. Portanto, faz sentido propor como objetivo de pesquisa a investigação do imaginário coletivo, aqui entendido como mundo dramaticamente habitado por mulheres que sofreram perda gestacional. Tal objetivo se justifica na medida em que pode ensejar a produção de conhecimento relevante para a clínica psicológica da maternidade e para profissionais preocupados com a saúde materno-infantil, bem como oferecer subsídios para debates que focalizam a melhoria das condições concretas de vida de mães, crianças e famílias em geral.

\section{Método}

Este estudo delineia-se como uma pesquisa qualitativa com uso do método psicanalítico, voltando-se à compreensão de sentidos de atos humanos, sempre considerados de modo contextualizado. Dentre o leque de opções teórico-metodológicas da perspectiva qualitativa, insere-se aquela, a que aderimos, que utiliza a psicanálise enquanto método investigativo.

A premissa básica desse método, utilizado em nossos estudos como meio para compreender os sentidos das diversas manifestações humanas, postula que toda conduta humana seria prenhe de sentido afetivo-emocional, independentemente de sua dimensão manifesta. Ou seja, todo ato humano estaria carregado de sentido, mesmo que possa parecer, à primeira vista, absurdo, cruel ou bizarro.

$\mathrm{Na}$ qualidade de elemento invariante do campo do conhecimento psicanalítico (Herrmann, 1979/2001), o método psicanalítico coloca-se como logicamente anterior às teorias e aos procedimentos clínicos, na medida em que é o caráter investigativo do método o que garante e valida a criação dos conhecimentos teóricos e permite o atendimento clínico em enquadre padrão ou em enquadres diferenciados. Não podemos nos esquecer de que o próprio Freud utilizou a psicanálise, enquanto método investigativo, na abordagem de materiais culturais, visando compreender a dimensão emocional dos atos humanos, como na Gradiva (Freud, 
1907/1955a), no Da Vinci (Freud, 1910/1955b) ou no Moises de Michelangelo (Freud, 1941/1955c). Além disso, também discutiu fenômenos sociais mais amplos, em obras como Mal-estar na civilização (Freud, 1930/1955f), Futuro de uma ilusão (Freud, 1927/1955e) e Psicologia das massas e análise do eu (Freud, 1921/1955d). Assim, demonstrou claramente que o uso do método se espraia para além de sua aplicação especificamente clínica, que ocorre no consultório.

Este método, articulado ao redor da associação livre e da atenção flutuante, permite a produção de interpretações sobre atos humanos, a partir das quais serão propostas compreensões, que ganham sentido em diferentes contextos teóricos psicanalíticos, usualmente conhecidos como escolas. Da nossa parte, cumpre esclarecer que adotamos como referencial a psicologia psicanalítica concreta de Bleger (1963/2007), vertente relacional (Greenberg \& Mitchell, 1983), que se diferencia de outras por valorizar consistentemente determinantes macrossociais dos atos humanos. Como leitor de Politzer (1928/1974), que distinguiu dois veios no texto freudiano, um de caráter energético, que dá origem a teorizações pulsionais, e um de caráter dramático, que se aproxima maximamente da fenomenologia do viver humano, Bleger (1963/2007) discute uma psicanálise dramática, articulando-a com o pensamento materialista, que tem na conduta humana, entendida como emergente de campos intersubjetivos, e não apenas como exteriorização do psiquismo individual, seu conceito nuclear.

A conduta corresponde a todo e qualquer ato humano que pode manifestar-se em três diferentes áreas de expressão: a) na área mental, b) na área corporal e c) na área da atuação no mundo externo, sendo que essa última inclui produtos da atividade humana, como artefatos, obras de arte e instituições (Bleger, 1963/2007). Todas as manifestações humanas estão carregadas de múltiplos sentidos - econômicos, históricos, culturais, cabendo à psicologia estudar os sentidos afetivo-emocionais, vale dizer o drama ou experiência vivida (Politzer, 1928/1974).

$\mathrm{Na}$ perspectiva da psicologia psicanalítica concreta, as condutas emergem de campos interpessoais, de caráter vincular-relacional, que podem ser denominados de campos de sentido afetivo-emocional. Tais campos são considerados como a dimensão não consciente das condutas. Ou seja, a dimensão inconsciente das condutas é entendida como configuração de sentido que se produz nas interações inter-humanas.

Constituídos pela mesma materialidade, que são os atos dos seres humanos concretos, campo e conduta não se diferenciam ontologicamente. Repetidamente encenados, os atos criam ambientes que, por seu turno, geram novos atos, que contribuirão para a reprodução ou para transformação dos campos. Assim, ambos os conceitos retratam a adoção de uma perspectiva ontológica de acordo com a qual a vida humana se dá no âmbito de uma realidade constituída por atos humanos, cujos fundamentos são afetivos e emocionais.

Entretanto, para facilitar a realização da pesquisa empírica com o método psicanalítico, um terceiro conceito, de caráter descritivo, também é aqui utilizado: o conceito de imaginário coletivo. Podemos defini-lo como atos e como campos de sentido afetivo por meio dos quais são criados mundos vivenciais regidos por certas crenças ou fantasias que, sendo humanamente criadas, impõem-se como verdades. Desse modo, o adjetivo imaginário não conota o que é falso, especular e/ou representacional, mas o que é resultado de criação, de produção humana. 
Visando estudar o imaginário coletivo sobre perda gestacional, decidimos utilizar, como material de pesquisa, manifestações sobre desafios e problemas da maternidade contemporânea, que se concretizam como postagens em blogues pessoais conhecidos como mommy blogs. Mesmo tendo sido realizadas em espaço público (Convery \& Cox, 2012; Dongre \& Sankaran, 2016; Salmons, 2017), tais comunicações são aqui manejadas segundo preceitos éticos de proteção à intimidade e ao anonimato de suas autoras, que norteiam toda pesquisa psicológica.

$\mathrm{Na}$ presente pesquisa, operacionalizamos o método psicanalítico em termos de procedimentos investigativos, a fim de cumprir nosso objetivo, além de tornar maximamente claro o caminho metodológico percorrido. Valemo-nos dos procedimentos investigativos de:

1. Seleção do material

2. Registro do material

3. Análise do material

Para cumprir o procedimento investigativo de seleção de postagens, realizamos levantamentos com o termo de busca "blogs mães perda gestacional" no Google. Para tanto, utilizamos os seguintes critérios definidos a priori:

1. Postagens provenientes de blogs pessoais brasileiros

2. Postagens escritas por internautas que se identificavam como mulheres que sofreram perda gestacional

3. Postagens que versavam sobre a experiência de perda gestacional

O uso desses critérios nos levou ao estudo das comunicações de 15 mães, que atenderam aos critérios estabelecidos. Identificamos cada mãe como M1, M2, etc.. Entendemos que esse número é suficiente para a produção de conhecimento aqui visada, considerando tanto que se trata de uma pesquisa qualitativa com uso do método psicanalítico, que adere aos pressupostos teóricos, epistemológicos e antropológicos da psicologia psicanalítica concreta.

Para cumprir o procedimento investigativo de registro do material, salvamos as 15 postagens em arquivos eletrônicos à parte. Realizamos a transcrição ipsis literis das narrativas com o intuito de preservar o material de um eventual desaparecimento da web, além de facilitar o trabalho de interpretação que exige leituras e releituras.

Atendendo ao procedimento investigativo de análise do material, visitamos as transcrições das postagens inúmeras vezes, no âmbito do grupo de pesquisa, à luz do método psicanalítico, a saber, em estado de atenção flutuante e associação livre de ideias. Lemos os escritos de modo a permitir a emergência de toda e qualquer lembrança, emoção, sentimento e associações em geral. Assim, numa trama de sentidos humanos, transferencialmente tecida, buscamos chegar interpretativamente aos determinantes não conscientes do material, ou seja, aos campos de sentido afetivo-emocional.

Finalizamos a pesquisa retomando os resultados interpretativas com vistas à realização do que habitualmente é designado como discussão. Na pesquisa qualitativa com método psicanalítico, essa parte do trabalho toma a forma de interlocuções reflexivas, que se constituem como retomada das questões levantadas pelos campos de sentido afetivo-emocional, com vistas a proceder a um trabalho de cunho reflexivo à luz da contribuição de outros autores. Nesta fase, suspendemos o uso do método psicanalítico para realizar um trabalho teórico-conceitual que não visa estabelecimento de leis gerais, mas aspira produzir conhecimento compreensivo. 


\section{Interpretações como resultados e interlocuções reflexivas como discussão}

A abordagem do material, no campo transferencial que se estabelece entre pesquisadores e postagens, favoreceu a enunciação de dois campos de sentido afetivo-emocional: "É culpa da mãe" e "Vazio eterno". O primeiro campo, que denominamos "É culpa da mãe", organiza-se ao redor da fantasia de que a mulher seria responsável pela morte do feto. O segundo campo, "Vazio eterno", organiza-se ao redor da fantasia de que a mulher, que vive uma perda gestacional, vivenciaria um sofrimento infinito.

\section{Refletindo sobre o campo "É culpa da mãe"}

O seguinte trecho ilustra adequadamente o posicionamento emocional contido no campo de sentido afetivo-emocional "É culpa da mãe", na medida em que vive a interrupção como uma queda: "Eu ainda me levanto, eu digo aos meus sentimentos de impotência e culpa por não ter conseguido levar a gravidez até o fim e dar à luz ao meu filho”.(M1)

No relato a seguir, a ideia de culpa está claramente associada à de fracasso pessoal, como se a perda resultasse de incompetência na realização de uma tarefa:

Viver duas experiências de perda seguidas sempre foi muito estranho para mim. Com esse meu segundo filho, sempre sentia que a minha dor era mais calejada, como se eu sofresse menos por ele não ter chegado a nascer e mais por mim, por ter fracassado novamente. (M1)

É importante lembrar que, enquanto fenômeno complexo, a gestação é permeada por sentimentos ambivalentes, nem sempre conscientes, (Borsa \& Dias, 2007) - entre querer e não querer, sentir-se capaz ou não, pensar que o momento é ou não é correto. $O$ trecho a seguir mostra um relato em que esta ambivalência está presente, trazendo muita culpa:

Sinto culpa... Acreditem ou não, eu sinto culpa. Sinto culpa porque no começo da gravidez do Lucas eu rezei mais para protege-lo, porque do Lucas eu me cuidei mais, e não tive medos. Deste eu tive. Lucas ocupa um espaço tão grande na minha e na vida de tanta gente que tive medo deste novo filho não conseguir ocupar espaço igual. (M12)

No exemplo acima, a mulher atribui a interrupção da segunda gestação ao fato de não ter desejado o segundo filho tão fortemente como desejou o primeiro.

Da mesma forma, a internauta, que aqui designamos como M12, também apresenta a fantasia de que espantou ou repeliu o feto:

Era porque um espírito estava prontinho para vir e ser gerado por mim... Mas na última hora desistiu, teve medo, ou eu o assustei, não sei! Sei que parece loucura pensar assim, mas é como eu penso e isso não dá para mudar muito. (M12)

Os resultados do estudo de Tachibana et al. (2014), realizado junto a uma equipe de enfermagem obstétrica, emergem a partir do mesmo tipo de campo de sentido afetivoemocional, uma vez que as enfermeiras tendiam a acreditar que o aborto era fruto de um desejo íntimo da gestante. De todo o modo, parece-nos importante ressaltar que, na perspectiva da psicologia psicanalítica concreta, os campos coletivamente produzidos são habitados por 
muitos, inclusive pelas próprias mulheres que passam por esse tipo de experiência. Assim, as crenças e fantasias tanto circulam no ambiente inter-humano como se traduzem como cobranças, que a pessoa faz a si própria, porque as internalizou, mesmo quando defensivamente quer atribui-las exclusivamente a outrem. Na verdade, o campo "É culpa da mãe" prefigura um verdadeiro julgamento, que acaba por sobrecarregar a mulher, como podemos observar no relato seguinte, feito por uma internauta que já tem uma criança:

O engraçado é que sinto as pessoas da minha família - e principalmente meu marido - mais preocupado nessa gestação. Cheguei a ouvir: "mas vai na padaria a pé por que? (Moro há meio quarteirão da padaria hahaha) E se você tropeça?" hahahah E foi sério. E isso se segue sobre viajar, sobre trabalho e etc. Coisa que ele não tinha na gestação anterior. (M14)

Apesar do aparente humor contido na narrativa, é possível perceber o sofrimento da mulher que luta para conciliar atividades, uma vez que trabalha e cuida da filha: "Nessa [gestação] eu não tinha nem a opção, seja pelos cuidados e rotina da Lourdes, seja pelo trabalho que está muito maior (graças à Deus)" (M14).

Sabemos que a própria psicanálise, a partir da concepção do determinismo intrapsíquico, contribuiu com este imaginário que responsabiliza a mulher, na medida em que dá suporte para a ideia de que a interrupção espontânea da gravidez poderia decorrer de desejos inconscientes. Soifer (1977/1980), ao tratar das ansiedades específicas presentes neste período de vida da mulher, afirma:

Cada um destes acessos de ansiedade, que podem durar dias ou semanas e chegar a produzir sintomatologia física própria, ou inclusive provocar aborto ou parto prematuro, caracterizase por fantasias bem determinadas e específicas, cujo conhecimento possibilita ao profissional realizar a higiene mental adequada, a fim de prevenir um ulterior agravamento (Soifer, 1977/1980, p. 21).

Langer (1953/1986), por sua vez, discute que, muitas gestantes vivenciariam inúmeras fantasias inconscientes ao longo do ciclo gravídico-puerperal, dentre as quais estariam aquelas que se baseiam em projeções duplas sobre o feto. De acordo com a autora, a mãe projeta, sobre o feto, a sua própria voracidade e a voracidade de sua mãe. A seu ver, essa dupla projeção geraria angústias tão intensas que poderiam levar a sentimentos de rejeição do feto que se concretizariam, eventualmente, como óbito fetal. De acordo com essa autora, a perda gestacional motivaria culpa por duas vias, a depender do amadurecimento da mulher. Pela primeira via, de caráter paranoide, a gestante esperaria sofrer retaliações por ter destruído o bebê num movimento de vingança contra a própria mãe. Pela segunda via, de caráter depressivo, sentir-se-ia triste pelo infortúnio do bebê e buscaria reparar o mal fantasiosamente cometido.

A nosso ver, as teorizações de Soifer (1977/1980) e de Langer (1953/1986) atribuem um peso muito grande a conflitos supostamente existentes entre a gestante e sua própria mãe. Fantasias de ataque aos bebês da própria mãe, ou de ter seus próprios bebês atacados, num movimento de retaliação, bastante conformes à sensibilidade teorizante kleiniana, parecem-nos aqui invocados de um modo discutível. Não desconhecemos, de modo algum, a importância dos vínculos familiares na etiologia de sofrimentos emocionais ligados à maternidade. Tampouco negamos que imaginários coletivos sobre a impossibilidade de realização da mulher 
sem filhos provocam sofrimentos emocionais. Contudo, questionamos o que nos parece um reducionismo psicológico duvidoso de fenômenos, certamente complexos, como são as intercorrências obstétricas.

Mesmo sem nos aprofundarmos na complexidade da gestação como fenômeno orgânico, lembramos que, desde o ponto de vista social e cultural, as relações de gênero predominantes na sociedade ocidental, fazendo-se de modo hierárquico e opressor, utilizam, ideologicamente, a crença num poderio feminino, de caráter maléfico, que seria o avesso da idealização materna. Desse modo, não nos parece incorreto o pensamento de que seja grande a abrangência da culpabilização materna, na sociedade em que vivemos, não nos parecendo descabida a noção de que a própria psicanálise tenha contribuído com uma excessiva responsabilização das mães, ao cogitar sobre a possibilidade destrutiva do inconsciente materno.

Considerando que nos baseamos em contribuições de Bleger (1963/2007), parece-nos interessante a possibilidade de ampliar e aprofundar o modo de entender a fantasia organizadora do campo "É culpa da mãe". A nosso ver, poderíamos, por essa via, favorecer o estabelecimento de relações que possam facilitar a sustentação, dispensada a mães, por profissionais e pela sociedade, de modo a acolhê-las num momento de dor, especialmente quando se trata de uma perda gestacional (Cunha, Pereira Junior, Caldeira \& Carneiro, 2016).

Nessa linha, acreditamos que as condições oferecidas, não somente pelos ambientes próximos, mas também pela sociedade maior, podem se revelar muito significativas em termos do desfecho da experiência de perda gestacional. Num ambiente claramente marcado por imaginários ambíguos em relação à maternidade, que a colocam como realização máxima do polo inferior da hierarquia de gênero, não seria difícil entender que o óbito fetal pode intensificar os efeitos persecutórios do campo "É culpa da mãe", o que, evidentemente, não contribuiria construtivamente para o amadurecimento emocional da mulher. Por outro lado, a constituição de ambientes sociais suficientemente bons poderia oferecer-se como sustentação a partir da qual a mulher poderia criar/encontrar seu estilo pessoal de lidar com a maternidade e suas vicissitudes (Granato \& Aiello-Vaisberg, 2003, 2005, 2013, 2016).

\section{Refletindo sobre o campo "Vazio eterno"}

O seguinte fragmento do relato, escrito por uma internauta que sofreu perda gestacional há 8 anos, é um exemplo de conduta emergente do campo de sentido afetivo-emocional intitulado "Vazio eterno": "Quem já perdeu um bebê sabe o quanto essa experiência pode ser devastadora. Neste dia, perdi também a fé em mim mesma e a vontade de viver" (M1)

O sofrimento da mulher decorrente da perda fetal nem sempre é reconhecido e devidamente valorizado (Camarneiro, Maciel \& Silveira, 2015), especialmente quando ocorre muito no início da gestação, sob o argumento de que não teria havido contato com o bebê. No entanto, observamos, no material de pesquisa, que, mesmo nestes casos, as mulheres sentem-se mães de um filho que morreu, como nos trechos seguintes: "Há três anos, engravidei e tive um aborto com 7 semanas. Parece pouco, mas esse bebê já era parte da família”.(M3)

Nunca vi meu filho, mas se ele soubesse o quanto me fez crescer, o quanto sua partida transformou meu ser e minha vida, acho que ele teria orgulho em dizer pros anjos que 
certamente o cercam que mesmo que só por 12 semanas de gestação, eu fui, eu sou a sua mãe. (M7)

Este fenômeno encontra fundamento em estudos psicológicos que apontam que o processo de se tornar mãe se inicia muito antes da gestação e segue seu curso com o nascimento do bebê (Piccinini et al, 2008). De fato, a gestação é um período repleto de grandes transformações em que surgem muitas fantasias, tais como a construção do bebê imaginado (Aiello-Vaisberg, 1999). O feto é fantasiado como um corpo inteiro com uma série de atributos, ou seja, um bebê formado. Tal construção imaginativa possibilita que a mãe constitua um espaço subjetivo para receber o recém-nascido na realidade. Desta forma, é plausível pensar que a interrupção da gestação implica na sensação de perda de um filho - que, em muitos casos, já tem nome - e não de um feto. Trata-se de uma experiência muito dolorosa de falta, por vezes, enlouquecedora, conforme pode ser observada no relato da internauta que teve a gestação de 6 meses espontaneamente interrompida e, depois, voltou a engravidar:

Posso dizer que eu sofri muito durante esse período de 2010 a 2014. era um vazio em mim e uma grande angústia e tristeza me acompanhavam. Eu tinha pesadelos, acordava gritando, dizendo que queria minha filha (era uma menina o bebê que perdi). (M5)

A sensação de desespero, com profundo comprometimento nas relações interpessoais familiares, foi relatada por uma mãe que sofreu aborto espontâneo na segunda gestação:

Não conseguia mais dormir, sonhava com meu filho todas as noites, com a progressão da gravidez e estava sempre chorando pelos cantos. Precisei e abusei de medicação para dormir. Toda aquela situação acabou culminando no meu divórcio pouco tempo após o aborto. (M7)

O intenso sentimento de vazio vivido pela mulher que sofreu uma perda fetal também foi encontrado no estudo de Faria-Schtzer et al. (2014). Estes autores apontam que a ideia da "criança morta" também traz a da "mãe morta". Lembram, também, que a construção real e imaginária da maternidade, que ocorre ao longo da gestação, é interrompida de forma abrupta, gerando a sensação de perda não apenas do feto, mas de tudo o que foi sonhado e idealizado (Camarneiro, Maciel \& Silveira, 2015), como podemos ler no relato da mulher cujo bebê morreu na $35^{\mathrm{a}}$ semana de gestação:

\footnotetext{
Nunca na minha vida imaginei que passaria por tamanho sofrimento. Tive o meu sonho destruído. Sabia que nunca mais teria o Miguel comigo, não o amamentaria, não iria sentir o seu cheirinho. Eu me sentia morta viva. Quando meu sogro colocou o caixão na cova eu morri junto. Metade de mim não existia mais (M8)
}

Considerando a complexidade do processo gestacional, que envolve fenômenos corporais, psicológicos e ambientais, julgamos fundamental refletir sobre o contexto cultural a partir do qual emerge o campo "Vazio Eterno". Nos relatos, observamos alusões a situações muito significativas para o universo da maternidade como, por exemplo, o dia das mães: "No sexto mês, eu tive um aborto. Foi o pior dia da minha vida. Dia das Mães de 2010. Assim foi o dia das mães para mim e para minha mãe, que não me abandonou um segundo”. (M5).

Caberia, aqui, questionar o uso do termo "destino" para caracterizar a busca feminina de realização pessoal por meio da maternidade, mesmo quando as mulheres já se percebem como pessoas que podem se inserir no mundo laboral, deixando a rotina do confinamento doméstico, 
que, aliás, nunca chegou a ser alcançada plenamente por aquelas mais desfavorecidas do ponto de vista econômico (Bueskens, 2018). A ideia de destino não se apresenta como na Grécia antiga, ligada aos desígnios dos deuses, mas emergente a partir de um imaginário que torna a mulher mais próxima da natureza do que o homem. Desse modo, tornar-se mãe corresponderia a para realizar seu destino natural, para que sua biologia se concretizasse organicamente. Como exemplo desse tipo de concepção, podemos citar um trecho bastante significativo do pensamento metapsicológico de Langer (1953/1986, p. 198), que a psicologia psicanalítica concreta, que adotamos, rejeita criticamente:

\begin{abstract}
A causa fundamental pela qual a mulher desejar ter um filho é biológica. Seu instinto maternal exige essa gratificação direta. Mas como o instinto sexual leva ao apaixonamento e os enamorados satisfazem em sua união, junto com seu apetite sexual, determinadas necessidades psicológicas, o instinto maternal, como parte integrante da sexualidade feminina, gratifica através de sua realização múltiplos desejos da mulher.
\end{abstract}

Alguns estudos, entre os quais podemos citar os de Martins, Azevedo e Afonso (2018) e de Mapelli et al. (2018), indicam que ainda persiste certa idealização da maternidade. Não soaria estranha, face essa idealização, uma fantasia de que a perda gestacional corresponderia a uma forma de punição da mulher que se sentiria, ao transitar pelo campo "Vazio eterno", como que condenada a um sofrimento infindável.

\title{
Refletindo sobre ambos os campos
}

Julgamos evidente que ambos os campos, aqui produzidos interpretativamente, encontramse profundamente interligados. Na medida em que o primeiro campo, "A culpa é da mãe", coloca a mulher numa situação imaginativa em que teria causado a perda gestacional, fomentando culpa, mais ou menos amadurecida, segundo caminhos paranoides ou depressivos, o segundo campo, "Vazio eterno", lançá-la-ia num ambiente imaginativo de acordo com o qual a interrupção da gravidez, enquanto um impedimento da maternidade, corresponderia a castigo merecido por toda a eternidade: "Demorou bastante para que eu entendesse que, no final das contas, é tudo uma dor só, uma imensa sensação de vazio por não ter conseguido levar a gravidez adiante e por perder aquele ser específico em formação". (M1)

Mais claramente, os campos, com os quais ora nos deparamos, parecem indicar um imaginário coletivo de acordo com o qual a mulher se sentiria culpada pela impossibilidade de continuar com a gestação, de modo a merecer um duro castigo que, na verdade, coincide com o próprio crime: não ter sido capaz de manter o filho é a falta paradoxalmente punida com a própria perda gestacional. Certos trechos são profundamente expressivos: "E dá-lhe mais ciclos de culpa e dor. Me sentia egoísta por não ter demonstrado meus sentimentos com a mesma intensidade que na primeira perda" (M1)

Ainda foi preciso contar para minha filha que ela não teria mais um irmão, e comunicar toda família. Meu mundo desmoronou, despois de voltar pra casa, não conseguia mais usar o banheiro, via o tempo todo meu filho ali, sozinho, ensanguentado, sem mim, e eu sem ele. Não conseguia mais ouvir minha filha me chamar de mãe, não sentia prazer no trabalho e cheguei a tentar suicídio (M7) 
Ao entrevistarem enfermeiras obstétricas, Tachibana et al. (2014), constataram a mesma configuração com a que aqui nos deparamos: que a interrupção da gestação era vista, pelas participantes, como um fenômeno que tanto marcaria a mãe com um sofrimento ininterrupto por toda a eternidade, quanto revelaria uma maldade inerente a esta mulher. Ou seja, as enfermeiras entrevistadas fantasiavam que a interrupção gestacional equivaleria a drama de enormes proporções. Tal configuração indica que os campos de sentido afetivo-emocional, produzidos interpretativamente, a partir da abordagem das enfermeiras, que convergem com o que encontramos estudando postagens de mães que sofreram óbito fetal, podem ser considerados como indícios de quão fortemente a maternidade é indicada, em nossa sociedade, como caminho para de realização feminina.

Constatamos que os cuidados infantis podem tomar diferentes formas nas diversas sociedades humanas. Em seus estudos, Gottlieb e DeLoache (2016) demonstram, com muita clareza e rigor, outras formas de organização destes cuidados. Por exemplo, numa tribo etíope, cuja religião é predominantemente muçulmana, a mãe seria a culpada caso o filho deixe de seguir o islamismo, porque teria passado maldade para a criança pelo leite. Logo, a mãe deveria ser extremamente zelosa com a saúde do filho e com a própria, do mesmo modo que toda a tribo deveria ser respeitosa e cuidadosa com a mãe. Por sua vez, nas Ilhas Faroé, toda a sociedade vê-se como responsável pelas crianças. Portanto, seria obrigação de todos criar um ambiente seguro para as novas gerações, cabendo ao sistema de saúde, o dever de favorecer a instauração e manutenção de uma rede de apoio para as mães. Deste modo, devemos reconhecer que os cuidados infantis se configuram como culturalmente determinados, tanto para nos atermos àquilo que as pessoas concretamente vivem, quanto para evitar naturalizações e abstrações sobre a maternidade.

Consistindo em meta, culturalmente produzida, que confere sentido à vida da mulher, como polo inferior da hierarquia de gênero, entendemos, portanto, que a mulher pode padecer de sofrimentos clinicamente relevantes quando sofre uma perda gestacional. Essa visão, veiculada pelo segundo campo, se articula ao primeiro campo, que responsabiliza a mulher pela ocorrência do óbito fetal. Ora, se tudo isso também se articula à noção de um destino determinado pela natureza, constatamos que essa não tem como efeito atenuar a culpa, como ocorre quando reconhecemos que alguém é doente, porque está implícita a aproximação do natural com o determinado pela vontade de Deus, de modo que o não cumprimento daquilo que seria desígnio natural remete, de modo implícito, à ideia de pecado.

Por fim, percebemos, em alguns trechos do material, a sobreposição dos dois campos "Vazio eterno" e "É culpa da mãe" -, ou seja, a presença da grande sensação de vazio e desespero, bem como do sentimento de culpa: "Perda gestacional. Independente de como é ou quando é, é, em sombra de dúvidas, uma dor sem fim. É um buraco que se abre, é uma culpa, um desespero, uma tristeza imensa". (M1)

Podemos considerar que ambos campos estão associados a sofrimento psíquico intenso, o que nos faz refletir sobre o suporte que estas mulheres e seus familiares necessitam, mas que nem sempre lhes é oferecido, como explícito no trecho:

Foram dias difíceis, de muita dor, e vivemos esse luto quase que sozinhos, pois poucos souberam lidar com o que tínhamos passado. Vi (e vejo até hoje) pessoas achando que minha dor não era tão grande, que foi bom assim, pois não convivi muito com ela, aí seria fácil 
esquecer. Como se eu tivesse perdido uma coisa qualquer, facilmente substituível! Diziam: “Ah, fica tranquila! Logo você engravida de novo!” Claro que eu queria engravidar de novo, mas um filho não substitui outro, nunca! Outros evitavam ao máximo falar sobre o assunto e até mesmo conversar comigo, pois não sabiam o que dizer. E sabe o que eu mais queria?!

Era falar sobre minha filha. (M6)

Ambos os campos se entrelaçariam, na nossa compreensão, porque o sofrimento é amplificado pela fantasia de ter causado a morte do feto. Estaríamos, portanto, diante de evidências que indicam que a experiência de óbito fetal se conforma, na nossa cultura, pelo menos até o momento, de modo radical, o que fica nítido quando uma internauta fala sobre uma perda gestacional que ocorreu logo no primeiro mês: "Não posso sequer falar que perdi o meu bebê porque não cheguei a ver feto nenhum, mas posso garantir que perdi um pouquinho de mim."(M12)

Essa manifestação, que, de um lado, é tocante, revela, por outro, problemas de amadurecimento que dificultam a visão do outro como singularidade irredutível. Tange, portanto, uma questão psicopatológica central, explorada como se significasse uma ligação afetiva dotada de grande intensidade, quando corresponde, de fato, à dificuldade de se discriminar do outro. Infelizmente, essa reação afetivo-emocional raramente é compreendida como sinal da necessidade de atenção psicológica clínica, mas acaba usada para manter imaginários conservadores, nos quais a mulher figura de modo distorcido, dificultando transformações no sentido de maior solidariedade e respeito entre as pessoas. Conviver proximamente com crianças e cuidar delas é uma atividade enriquecedora e realizadora para todos, não se reduzindo a uma prerrogativa feminina.

\section{Limitações do estudo e sugestões para trabalhos futuros}

Malgrado às limitações inerentes à pesquisa empírica, entendemos que este trabalho possibilitou iluminar uma parte da dimensão afetiva-emocional, de caráter não consciente, que embasa a ocorrência da perda gestacional. Considerando que esta investigação limitou-se a estudar as postagens de mulheres que sofreram perda gestacional, sugerimos, para estudos futuros, a abordagem de outros materiais de pesquisa de tipo cultural, como filmes e produções literárias, que complementariam o que se pode apreender em outros espaços da internet, como YouTube ou Instagram, ou ainda nas entrevistas psicológicas. Não menos importante, entendemos, como possibilidade de trabalho futuro, escutar mulheres, mães e não mães, de diferentes faixas etárias, sobre a maternidade, além de outros familiares e profissionais de saúde.

\section{Referências}

Aiello-Vaisberg, T. M. J. A. (1999). Sonhos de nascimento e preocupação materna primária. Psyche, 4, 131-143. 
Aiello-Vaisberg, T. M J. (2017). Estilo clínico ser e fazer: resposta crítico-propositiva a despersonalização e sofrimento social. Boletim - Academia Paulista de Psicologia, 37(92), 41-62. Disponível em http://pepsic.bvsalud.org/scielo.php?script=sci_arttext\&pid=S1415711X2017000100005\&lng=pt\&tlng=pt.

Ambrosio, F. F. (2013). O estilo clínico "Ser e Fazer" na investigação de benefícios clínicos de psicoterapias. (Tese de Doutorado, Pontifícia Universidade Católica de Capinas). Recuperado de http://tede.bibliotecadigital.puccampinas.edu.br:8080/jspui/bitstream/tede/452/1/Fabiana\% 20Follador\%20e\%20Ambrosio.pdf

Badinter, E. (1981). Mother love: Myth and reality: Motherhood in modern history. New York, USA: Macmillan.

Badinter, E. (2012). The conflict: Woman \& Mother. Melbourne, Australia: Text Publishing.

Barr-Walker, J., Jayaweera, R. T., Ramirez, A. M., \& Gerdts, C. (2019). Experiences of women who travel for abortion: A mixed methods systematic review. PLOS ONE, 14(4), 1-26. doi: https://doi.org/10.1371/journal.pone.0209991.

Bleger, J. (2007). Psicologia de la conducta. Buenos Aires: Paidós. (Original publicado em 1963).

Borsa, J. C., \& Dias, A. C. G. (2007). Considerações acerca da relação mãe-bebê da gestação ao puerpério. Contemporânea: Psicanálise e Transdisciplinaridade, 2, 310-321.

Bueskens, P. (2018). Modern motherhood and women's dual identities: Rewriting the sexual contract. Londres: Routledge.

Camarneiro, A. P. F., Maciel, J. C. S. C., \& Silveira, R. M. G. D. (2015). Vivências da interrupção espontânea da gravidez em primigestas no primeiro trimestre gestacional: um estudo fenomenológico. Revista de Enfermagem Referência, (5), 109-117. doi: http://dx.doi.org/10.12707/RIV14064.

Cardoso-Escamilla, M. E., Zavala-Bonachea, M. T., \& Alva-López, M. D. C. (2017). Depresión y estrés postraumático en mujeres con pérdidas gestacionales inducidas e involuntarias. Pensamiento Psicológico, 15(2), 109-120. doi: http://dx.doi.org/10.11144/Javerianacali.PPSI15-2.depm.

Collardeau, F., Corbyn, B., Abramowitz, J., Janssen, P. A., Woody, S., \& Fairbrother, N. (2019). Maternal unwanted and intrusive thoughts of infant-related harm, obsessivecompulsive disorder and depression in the perinatal period: study protocol. BMC Psychiatry, 19(1), 94. doi: https://doi.org/10.1186/s12888-019-2067-x.

Convery, I., \& Cox, D. (2012). A review of research ethics in internet-based research. Practitioner Research in Higher Education, 6(1), 50-57.

Cunha, A. C. B. da, Pereira Junior, J. P., Caldeira, C. L. V., \& Carneiro, V. M. S. de P. (2016). Diagnóstico de malformações congênitas: impactos sobre a saúde mental de gestantes. Estudos de Psicologia, 33(4), 601-611. doi: https://doi.org/10.1590/198202752016000400004. 
Dongre, A. R., \& Sankaran, R. (2016). Ethical issues in qualitative research: Challenges and options. International Journal of Medical Science and Public Health, 5(6), 1-8. doi: 10.5455/IJMSPH.2016.19102015179.

Faria-Schtzer, D.B., Lovorato Neto, G., Duarte, C.A.M., Vieira, C.M. \& Turato, E.R. (2014). Fica um grande vazio: Relatos de mulheres que experienciaram morte fetal durante a gestação. Estudos Interdisciplinares em Psicologia, 5(2), 113-132. doi: http://dx.doi.org/10.5433/2236-6407.2014v5n2p113.

Federici, S. (2019). Calibã e a bruxa. Mulheres, corpo e acumulação primitiva. Rio de Janeiro, RJ: Editora Elefante.

Freud, S. (1955a). Delusion and dream in Jensen's Gradiva. The standard edition of the complete psychological works of Sigmund Freud, vol. IX. Londres: The Hogarth Press and the Institute of Psychoanalysis. (Original publicado em 1907).

Freud, S. (1955b). Leonardo da Vinci and a memory of his childhood. The standard edition of the complete psychological works of Sigmund Freud, vol. XI. Londres: The Hogarth Press and the Institute of Psychoanalysis. (Original publicado em 1910).

Freud, S. (1955c) The Moses of Michelangelo. The The standard edition of the complete psychological works of Sigmund Freud, vol. XIII. Londres: The Hogarth Press and the Institute of Psychoanalysis. (Original publicado em 1914).

Freud, S. (1955d). Group psychology and the analysis of the ego. The The standard edition of the complete psychological works of Sigmund Freud, vol. XVIII. Londres: The Hogarth Press and the Institute of Psychoanalysis. (Original publicado em 1921).

Freud, S. (1955e) The future of an illusion. The The standard edition of the complete psychological works of Sigmund Freud, vol. XXI. Londres: The Hogarth Press and the Institute of Psychoanalysis. (Original publicado em 1927).

Freud, S. (1955f). Civilization and its discontents. The The standard edition of the complete psychological works of Sigmund Freud, vol. XXI. Londres: The Hogarth Press and the Institute of Psychoanalysis. (Original publicado em 1930).

Giddens, A. (2013). The transformation of intimacy: Sexuality, love and eroticism in modern societies. Hoboken, USA: John Wiley \& Sons.

Gottlieb, A., \& DeLoache, J. S. (2016). A world of babies: Imagined childcare guides for eight societies. Cambridge: Cambridge University Press.

Granato, T. M. M., \& Aiello-Vaisberg, T. M. J. (2003). Ser e fazer na maternidade contemporânea. Estudos de Psicologia, 20, 71-76. doi: https://doi.org/10.1590/S0103166X2003000200007.

Granato, T. M. M., \& Aiello-Vaisberg, T. M. J. (2005). Prímula e Narciso a caminho da preocupação materna primária. Mudanças: Psicologia da Saúde, 13, 364-373. doi: https://doi.org/10.15603/2176-1019/mud.v13n2p364-373.

Granato, T. M., \& Aiello-Vaisberg, T. M. J. (2013). Narrativas interativas sobre o cuidado materno e seus sentidos afetivo-emocionais. Psicologia Clínica, 25(1), 17-35. doi: https://doi.org/10.1590/S0103-56652013000100002. 
Granato, T. M. M., \& Aiello-Vaisberg, T. M. J. (2016). Interactive narratives in the investigation of the collective imaginary about motherhood. Estudos de Psicologia, 33(1), 25-35. doi: https://doi.org/10.1590/1982-02752016000100004.

Greenberg, J. R. \& Mitchell, S. A. (1983). Object Relations in Psychoanalytic Theory. Cambridge, USA, and Londres: Harvard University Press.

Hamad, R., Modrek, S., \& White, J. S. (2019). Paid family leave effects on breastfeeding: A Quasi-Experimental study of US Policies. American Journal of Public Health, 109(1), 164166. doi: https://doi.org/10.2105/AJPH.2018.304693.

Herrmann, F. (2001). Andaimes do real: o método da psicanálise. São Paulo, SP: Casa do Psicólogo. (Original publicado em 1979).

Hollway, W. (2011). Rereading Winnicott's 'Primary maternal preoccupation'. Feminism \& Psychology, 22(1), 20-40. doi: https://doi.org/10.1177/0959353511411692.

Komtenza, B., Satyanarayana, S., Takarinda, K. C., Mukungunugwa, S. H., Mugurungi, O., Chonzi, P., Sithole, N., Bvochora, T., Mushavi, A. (2019) Identifying high or low risk of mother to child transmission of HIV: How Harare City, Zimbabwe is doing? PLoS ONE, 14(3), 1-10. doi: https://doi.org/10.1371/journal.pone.0212848.

Langer, M. (1986). Maternidade e sexo. Porto Alegre: Artes Médicas. (Original publicado em 1953).

Lemos, L. F. S. \& Cunha, A. C. B. da. (2015). Concepções Sobre Morte e Luto: Experiência Feminina Sobre a Perda Gestacional. Psicologia: Ciência e Profissão, 35(4), 1120-1138.

Mapelli, L.D., Barbieri, M.C., Castro, G.V.D.Z.B., Bonelli, M.A., Wernet, M., \& Dupas, G. (2018). Child with autistic spectrum disorder: care from the family. Escola Anna Nery, 22(4), e20180116. doi: http://dx.doi.org/10.1590/2177-9465-ean-2018-0116.

Marchesi, S. (2018). The natural mother: Discourse and representation of motherhood in an Italian Facebook group. (Dissertação de Mestrado, Universidade de Linköping). Recuperado de http://www.diva-portal.org/smash/get/diva2:1229897/FULLTEXT01.pdf

Martins, P.L., Azevedo, C.S., \& Afonso, S.B.C. (2018). O papel da família nos planos de tratamento e no cuidado pediátrico hospitalar em condições crônicas complexas de saúde. Saúde e Sociedade, 27(4), 1218-1229. doi: https://doi.org/10.1590/s0104-12902018170402.

Mutiso, S. K., Murage, A., \& Mukaindo, A. M. (2018). Prevalence of positive depression screen among post miscarriage women - A cross sectional study. BMC Psychiatry, 18(1), 32. doi: https://doi.org/10.1186/s12888-018-1619-9.

Piccinini, C.A., Lopes, R.S., Gomes, A.G. \& De Nardi, T. (2008). Gestação e a constituição da maternidade. Psicologia em Estudo, 13(1), 63-72. doi : https://doi.org/10.1590/S141373722008000100008 .

Politzer, G. (1974). Critique des fondements de la psychologie. Paris: PUF. 1974. (Original publicado em 1928). 
Salmons, J. (2017). "Getting to Yes: Informed Consent in Qualitative Social Media Research". In K. Woodfield (Ed.) The Ethics of Online Research (Advances in Research Ethics and Integrity, Vol. 2). Bingley, UK: Emerald Publishing Limited.

Scavone, L. (2004). Dar a vida e cuidar da vida feminismo e ciências sociais. São Paulo, SP: Unesp.

Schulte, A., Gallo-Belluzzo, S. R., \& Aiello-Vaisberg, T. M. J. (2019). A experiência emocional de autoras de mommy blogs. Estudos Interdisciplinares em Psicologia, 10(1), 107-130. doi: 36-6407.2019v10n1p107.

Soifer, R. (1980). Psicologia da gravidez, parto e puerpério. Porto Alegre, RS: Artes Médicas. (Original publicado em 1977).

Tachibana, M., Ambrosio, F. F., Beaune, D., \& Vaisberg, T. M. J. A. (2014). O imaginário coletivo da equipe de enfermagem sobre a interrupção da gestação. Ágora: Estudos em Teoria Psicanalítica, 17(2), 285-297. doi: https://doi.org/10.1590/S151614982014000200009.

Tavoli, Z., Mohammadi, M., Tavoli, A., Moini, A., Effatpanah, M., Khedmat, L., \& Montazeri, A. (2018). Quality of life and psychological distress in women with recurrent miscarriage: a comparative study. Health And Quality Of Life Outcomes, 16(1), 150. doi: https://doi.org/10.1186/s12955-018-0982-z.

Vásquez, G. (2014). Maternidade e feminismo: Notas sobre uma relação plural. Revista Trilhas da História, 3(6), 167-181.

Visintin, C. D. N., \& Aiello-Vaisbgerg, T. M. J. (2017). Motherhood and social suffering in Brazilian mommy blogs. Psicologia: Teoria e Prática, 19(2), 108-116. doi: http://dx.doi.org/10.5935/1980-6906/psicologia.v19n2p108-116.

Revisão gramatical: Fabiana Follador e Ambrosio

E-mail: fabfoll@gmail.com

Recebido em novembro de 2019 - Aceito em junho de 2020. 